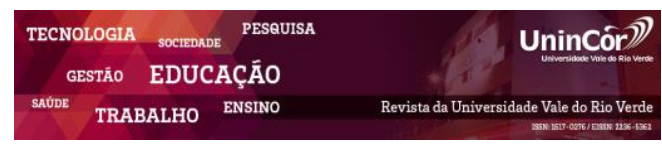

Revista da Universidade Vale do Rio Verde ISSN: 1517-0276 / EISSN: 2236-5362 v. $16\left|\mathbf{n}^{\circ} .3\right|$ Ano 2018

Francisco Carlos Pedro

Empresa de Assistência Técnica e Extensão Rural do Estado de Minas Gerais (Emater MG) francisco@emater.mg.gov.br

Aurivan Soares de Freitas Universidade Vale do Rio Verde (UninCor) aurivan.soares@hotmail.com

Eliana Alcantra

Universidade Vale do Rio Verde (UninCor) prof.eliana.alcantra@unincor.edu.br

Jeferson Arantes Braz Universidade Vale do Rio Verde (UninCor) jefersonbras_1991tc@hotmail.com

Júnia Rafael Mendonça Figueiredo Universidade Vale do Rio Verde (UninCor) prof.junia.figueiredo@unincor.edu.br

\section{UTILIZAÇÃO DE EQUIPAMENTOS DE PROTEÇÃO INDIVIDUAL E AGROTÓXICOS POR PRODUTORES RURAIS DE TRÊS CORAÇÕES - MG}

\section{RESUMO}

A exposição inadequada de agrotóxicos causa problemas à saúde e ao ambiente, por isso, durante a manipulação desses produtos é indispensável o uso de equipamentos de proteção individual (EPI's) para o aplicador. Dessa forma, objetivou-se com o presente estudo verificar o manuseio, o conhecimento e a forma de utilização do EPI's pelos aplicadores que manipulam agrotóxicos em suas propriedades. O trabalho foi realizado com produtores e filhos de produtores, estudantes do primeiro ao décimo período de Agronomia da UninCor de Três Corações MG, por meio de uma pesquisa quali-quantitativa. Foram utilizados questionários para levantamento de dados, abordando o nível de conhecimento e o grau de compreensão a respeito da aquisição, manipulação, aplicação, devolução das embalagens vazias de agrotóxicos. Constatou-se que $100 \%$ dos entrevistados fizeram uso de agrotóxicos no último ano. Verificou-se que $87,5 \%$ dos entrevistados adquiriram os agrotóxicos com o auxílio de uma assistência técnica e, durante a aplicação, somente 33,3\% dos produtores tiveram o acompanhamento técnico. Em relação aos EPI's, 79,2\% dos produtores afirmaram utilizarem corretamente, contudo, $63,7 \%$ desses não usaram os procedimentos técnicos adequados para se vestir e tirar os equipamentos. Nestas propriedades, 66,7\% dos EPI's estavam em condições indicadas para uso. Em 54,2\% das propriedades não apresentaram um local adequado e exclusivo para guarda dos produtos. No caso da devolução das embalagens de agrotóxicos, 62,5\% disseram que devolvem no local indicado pelo receituário agronômico. Diante do exposto, são necessárias orientações são indicadas para melhor esclarecer o uso e manipulação de agrotóxicos aos aplicadores.

Palavras-Chave: EPI's. Contaminação. Toxidez. Período de Carência. Agrotóxicos

\section{USE OF PERSONAL PROTECTIVE EQUIPMENT AND PESTICIDES BY FARMERS OF TRÊS CORAÇÕES - MG}


understanding regarding the acquisition, manipulation, application, and return of empty agrochemical containers. It was verified that $100 \%$ of the interviewees made use of pesticides in the last year. It was verified that $87.5 \%$ of the interviewees acquired the agrochemicals with the aid of a technical assistance and, during the application, only $33.3 \%$ of the producers had the technical follow-up. Regarding PPE, $79.2 \%$ of the producers claimed to use it correctly, however, $63.7 \%$ of them did not use the proper technical procedures to dress and remove the equipment. In these properties, $66.7 \%$ of PPE's were in conditions indicated for use. In $54.2 \%$ of the properties did not present an adequate and exclusive place to guard the products. In the case of the return of the containers of pesticides, $62.5 \%$ said that they return in the place indicated by the agronomic prescription. In view of the above, guidelines are needed to better clarify the use and handling of pesticides to the applicators.

Keywords: PPE's. Contamination. Toxicity. Grace period. Pesticides.

Recebido em: 02/08/2018 - Aprovado em: 22/10/2018- Disponibilizado em: 30/12/2018

\section{INTRODUÇÃO}

Os defensivos agrícolas, também denominados de agrotóxicos, produtos fitossanitários, agroquímicos ou pesticidas são, produtos químicos utilizados no meio rural para reduzir as perdas de produtividade, causadas principalmente pelo ataque de pragas, doenças e plantas daninhas (RECENA et al., 2006).

$\mathrm{O}$ uso de agrotóxicos em âmbito mundial intensificou-se entre as décadas de 60 e 70 com a "Revolução Verde". No Brasil, o uso de agrotóxicos começou nessa mesma época, quando ocorreu a adoção de um pacote conhecido como "modernização da agricultura". Assim, o Brasil se tornou um dos maiores países agrícolas, o qual utiliza $20 \%$ de todo agrotóxico do mundo, sendo o maior consumidor de agrotóxicos (SILVA, 2015). Segundo Silva (2015), Minas Gerais é um dos estados que mais comercializam agrotóxicos no país, correspondendo a $1,78 \%$ de todo o consumo.
No entanto, na maioria dos casos, não existe controle eficaz sobre a venda e uso desses produtos, bem como sobre a utilização de equipamentos de proteção (NEVES, 2001; RAMOS \& SILVA FILHO, 2004; TRAPÉ, 1993), o que pode causar danos à saúde do agricultor e ao meio ambiente.

Para a saúde, os agrotóxicos podem provocar intoxicações agudas ou crônicas. No primeiro caso, os sintomas manifestam-se mais rapidamente no organismo em formas de dores de cabeça, dores de estômago, sonolência, tontura, fraqueza, perturbação da visão, saliva e suor excessivos, dificuldade respiratória e diarreia. $\mathrm{Na}$ forma crônica, os efeitos da intoxicação podem surgir meses ou até anos depois da exposição ao produto. Esse tipo de manifestação pode levar ao desenvolvimento de certos tipos de paralisias e de doenças como o câncer de DPOC (Doença Pulmonar Obstrutiva Crônica). A contaminação acontece por via aérea (respiração), digestão (ingestão) ou pela pele 
(contato direto) (ROCHA, 2004), assim é essencial que sejam utilizados equipamentos de proteção individual (EPI's), para que a aplicação de produtos fitossanitários ocorra de forma segura (AGOSTINETTO et al., 1998).

A utilização ineficiente dos EPI's representa grande perigo à saúde do aplicador, causando elevação significativa no número de intoxicações. Neste aspecto deve-se enfatizar que o uso de EPI's é um ponto de segurança do trabalho que requer ação técnica, educacional e psicológica para a sua aplicação.

O manuseio inadequado de agrotóxicos pode propiciar fluxo livre desses agentes químicos no meio ambiente, o que significa, em última análise, degradação ambiental e danos à saúde das pessoas que habitam a zona rural (AGOSTINETTO et al., 1998). Por esses motivos, além da proteção com EPI's é necessária que seja realizada a destinação adequada das embalagens vazias dos agrotóxicos (ANDEF, 2010).

Devido a esses problemas, objetivou-se com o presente estudo verificar o conhecimento e a forma de uso de agrotóxicos por produtores e trabalhadores rurais da região rural do município de Três Corações - MG.

\section{MATERIAL E MÉTODOS}

O trabalho foi realizado com 24 produtores e filhos de agricultores, estudantes do primeiro ao décimo período do curso de Agronomia da UninCor de Três Corações, através uma pesquisa quali-quantitativa durante o mês de maio de 2017.

Foi utilizado um roteiro com 25 questões abordando o nível de conhecimento e o grau de compreensão a respeito de vários aspectos, conforme o quadro 1 . O questionário foi composto por 25 perguntas, subdividido em duas partes sendo elas: perfil do produtor/aluno entrevistado, contendo cinco perguntas e impactos socioambientais no conhecimento, manipulação e uso dos agrotóxicos, com vinte perguntas.

Quadro 1 - Questões abordados durante a entrevista.

Como são adquiridos os agrotóxicos e acompanhamento do receituário, se são registrados para a cultura do café (MAPA) e cadastrados (IMA).

Se há anotações das aplicações discriminadas por área, quantidade, data e aplicador.

Uso de EPI's e procedimentos adotados e verificação visual se o EPI's está em condições adequadas de uso.

Uso de sinalizações para os períodos de reentrada, constatação visual e verificação de registros.

Se há o uso de sinalizações para indicarem os períodos de carência, constatação visual e verificação de registros.

Se o local é adequado para guarda exclusiva dos agrotóxicos, com dimensões mínimas necessárias, piso pavimentado, coberto, identificado, arejado, trancado, afastado de residências e fontes de água.

Se as embalagens sofreram a tríplice lavagem e após a inutilização (perfurando o fundo da mesma) e acondicionamento em local seguro.

Se houve a devolução de embalagens por meio de Nota Fiscal carimbada pelo recebedor das embalagens ou recibos de devolução. 
Os resultados foram expressos como distribuição da frequência e computada a porcentagem de respondentes para cada questão. Os dados foram tabulados e analisados por meio de estatística descritiva no programa computacional Microsoft Excel, versão 2010.

\section{RESULTADOS E DISCUSSÃO}

De acordo com os dados, $41,7 \%$ dos entrevistados tinham até 25 anos, 16,7\% tinham entre 25 a 35 anos, 8,3\% entre 35 a 45 anos, $4,2 \% 45$ a 55 anos, $25,0 \%$ entre 55 a 65 anos e $4,2 \%$ com idade superior a 65 anos, sendo a média dos produtores entrevistados de 36,5 anos de idade, (Figura 1). E a família destes entrevistados tem uma média de 4,8 pessoas.

Figura 1 - Idade dos entrevistados.

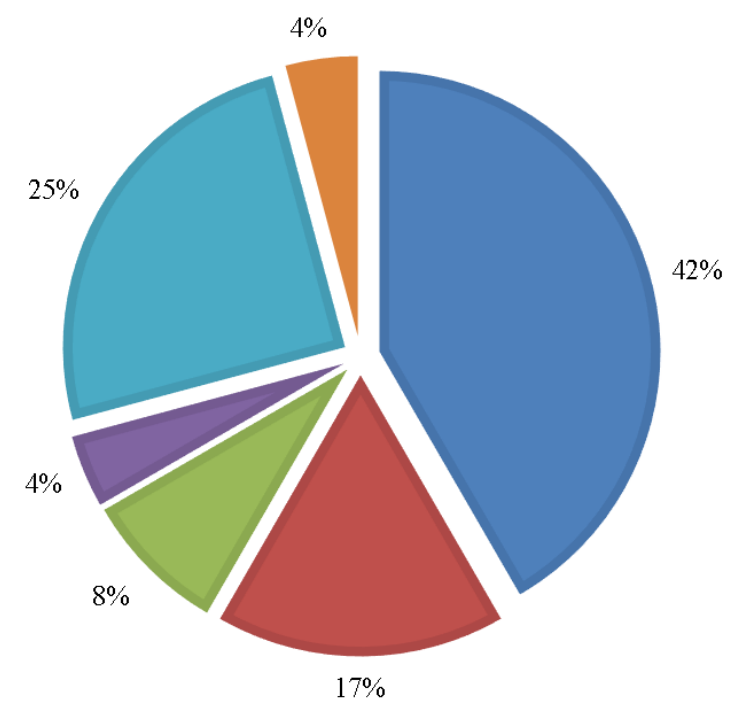

$$
\begin{aligned}
& \text { घidade }<25 \text { anos } \square \text { idade } 25 \text { a } 35 \text { anos } \quad \text { idade } 35 \text { a } 45 \text { anos } \\
& \text { "idade } 45 \text { a } 55 \text { anos }=\text { idade } 55 \text { a } 65 \text { anos }=\text { idade }>65 \text { anos }
\end{aligned}
$$

Em se tratando do tamanho das propriedades, em hectares (ha), verificou-se que $70,8 \%$ das propriedades apresentam tamanho de até 50 há, 12,5\% apresentam entre 50 e 100 ha e $16,6 \%$ são maiores que 100 ha.

Observando as atividades desenvolvidas dentro das 24 propriedades, o café está presente em $75 \%$ delas, o milho em $41,7 \%$, a pecuária de leite em $25 \%$, a pecuária de corte em $25 \%$, e outras atividades foram representadas por $41,7 \%$, incluindo a cultura do eucalipto, soja e trigo (Figura 2). Esses dados refletem a importância socioeconômica do café para a região, seguido de milho e pecuária.

Figura 2 - Principais atividades agropecuárias desenvolvidas pelos entrevistados.

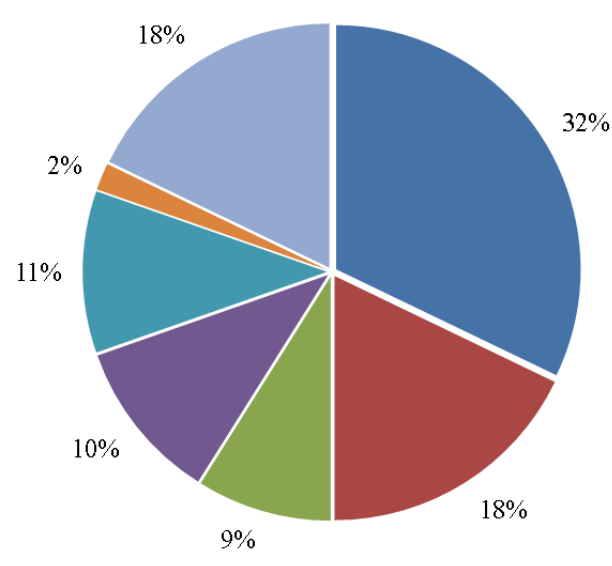

$$
\begin{aligned}
& \text { - Café Milho } \quad \text { Feijão } \\
& \text { - Pecuária de Leite } \quad \text { Pecuária de Corte } \quad \text { Pecuária Mista } \\
& \text { - Outras }
\end{aligned}
$$

Todas essas culturas produzidas podem ser afetadas por diversas pragas, como insetos, patógenos e plantas invasoras. Dessa forma, para combater estes organismos, muitas vezes são utilizados produtos químicos, como inseticidas, fungicidas, acaricidas, nematicidas, bactericidas e vermífugos (ALVES FILHO, 2002; SANTOS \& PYHN, 2003), o que pode ser constato nesse trabalho, visto que, $100 \%$ dos entrevistados fizeram uso agrotóxico no último ano. No entanto, em apenas $50 \%$ dos produtos utilizados foi feita aplicação controlada, com anotação das áreas ou glebas tratadas, data e quantidade aplicada e aplicador. 
Além disso, 8,3 \% dos agrotóxicos utilizados não eram registrados no Ministério da Agricultura Pecuária e Abastecimento (MAPA) e no Instituto Mineiro de Agropecuária (IMA) para a cultura em questão (Figura 3).

Figura 3 - Principais resultados obtidos.

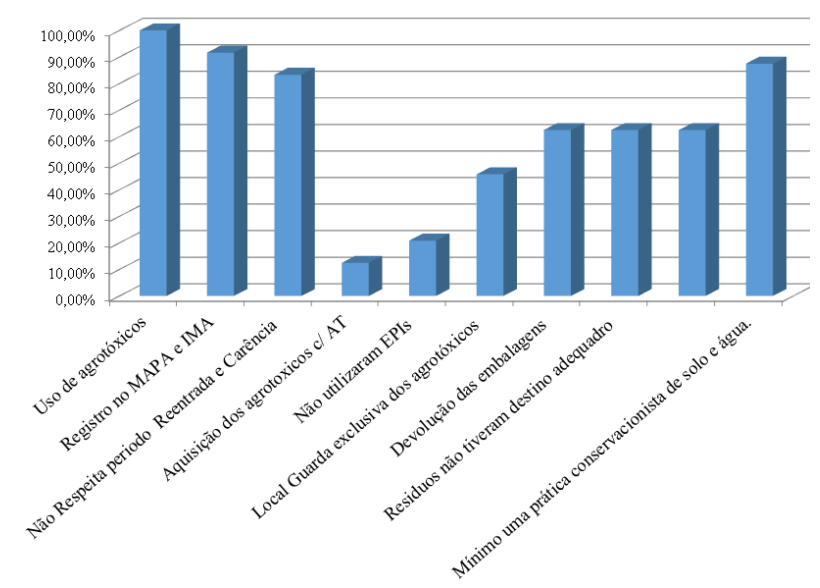

Para a aquisição dos produtos, verificou-se que $87,5 \%$ dos entrevistados adquiriram os agrotóxicos com o auxílio de uma assistência técnica e, durante a aplicação, 33,3\% dos produtores tiveram o acompanhamento técnico. Os demais $66,7 \%$ não utilizaram $o$ acompanhamento técnico. Essa falta de apoio técnico e o despreparo da população para a manipulação destas substâncias contribuem para a exposição da população aos pesticidas (SILVA et al, 2001). O que pôde ser constato nesse trabalho, pois mesmo que $79,2 \%$ dos produtores afirmem que utilizam EPI's, 63,7\% desses não usaram os procedimentos técnicos adequados para se vestir e tirar os EPI's. Além disso, nas mesmas propriedades, apenas $66,7 \%$ dos EPI's estavam em condições de uso.

Essa falta de cuidado durante a aplicação dos agrotóxicos pode gerar prejuízos à saúde, visto que, o agricultor desprotegido tem as chances de intoxicação aumentadas em 72\%. Em dois trabalhos realizados em Minas Gerais, foi possível perceber que $50 \%$ e $41 \%$ dos trabalhadores estavam intoxicados (OLIVEIRASILVA et al., 2001; SOARES, ALMEIDA \& MORO 2003). Além disso, o risco de intoxicação aumenta $43 \%$ quando o agricultor entre em contato com o produto em um intervalo de tempo menor que 15 dias (SOARES, ALMEIDA \& MORO, 2003), no entanto, no presente trabalho, observou-se que apenas $16,6 \%$ e $16,7 \%$ das propriedades utilizam sinalizadores para os períodos de reentrada e período de carência, respectivamente, o que facilita esse novo contato.

Quando questionados sobre o local adequado para guarda dos agrotóxicos, com dimensões mínimas necessárias, piso pavimentado, coberto, identificado, arejado, trancado, afastado de residências e fonte de água, foram constatados que $45,8 \%$ destas propriedades apresentaram um local adequado, contra $54,2 \%$ que não apresentaram um local adequado para guardar agrotóxicos. De acordo com Castro, Ferreira e Mattos (2011) quando pesquisaram o uso de agrotóxicos em dois assentamentos de reforma agrária em Russas, CE, e verificaram que a maior parte dos entrevistados armazenavam os agrotóxicos em suas residências ou o depositavam fora, junto a outros materiais, sem definir uma distância mínima de segurança, o que causa danos à saúde da população local.

Além disso, apenas 58,3\% dos agricultores fazem a tríplice lavagem das embalagens vazias, e acondicionam em locais seguros, o que 
aumenta o risco de contaminação e diminui o aproveitamento integral do produto (QUINTELA, 2004). No entanto, 62,5\% dos entrevistados devolvem as embalagens posto indicado no receituário agronômico, mesmo que não estejam conforme indicação, assim apenas $58,3 \%$ afirmaram possuir os recibos ou notas fiscais carimbadas confirmando a devolução, contra 41,7\% não terem a comprovação da devolução das embalagens.

Na questão sobre a destinação adequada dos resíduos de agrotóxicos (lavagem dos EPI's e equipamentos) apenas $37,8 \%$ faziam adequadamente. Por outro lado, 62,2\% dos produtores afirmaram não dar destinos adequados e seguro para os resíduos, contaminando assim o ambiente.

Além das questões sobre descarte das embalagens, os entrevistados foram questionados quanto à distância em que os agrotóxicos são manipulados dos mananciais, visto que, mesmo que os agrotóxicos sejam aplicados nas plantas podem ser contaminar lençóis freáticos devido a lixiviação da água e erosão dos solos (SCORZA et al., 2010). Além disso, a contaminação também pode ocorrer superficialmente, devido à ligação dos sistemas hídricos, atingindo áreas distantes do local de aplicação do agrotóxico (BRIGANTE et al., 2002; VEIGA et al, 2006). Essa contaminação pode tornar a água imprópria para o consumo (FOSTER et al., 2006). No entanto, de acordo com os entrevistados, 37,5\% das propriedades manipulam as substâncias à menos de 30 metros, $8,3 \%$ entre 30 e 50 metros e $54,7 \%$ acima de 50 metros.

Todavia, durante os questionamentos ficou evidenciado que $87,5 \%$ dos entrevistados afirmaram ter utilizados meios para minimizar impactos ambientais na propriedade, sendo relatado por alguns proprietários rurais o uso de práticas relacionada a conservação do solo, água ou vegetação entre outros. Contudo, os resultados apontaram, também, que cerca de 50\% dos entrevistados ainda desconhecem qualquer tipo de informações sobre os impactos que afetam diretamente a sustentabilidade da região de Três Corações, principalmente os impactos socioambientais. Neste sentido, Londres (2011) salienta que a fiscalização pelo serviço público quanto às aplicações e utilização de produtos ilegais é inoperante. Já Bedor et al. (2009), salientam ainda que a falta de fiscalização no acompanhamento técnico e no controle de agrotóxicos faz com que a tomada de decisão do agricultor seja baseada apenas na produtividade, sem levar em consideração outros fatores relativos à saúde e ao meio ambiente.

\section{CONCLUSÕES}

Constatou-se que os aplicadores dos agrotóxicos destas propriedades fizeram o uso inadequado dessas substâncias por não apresentarem conhecimentos para a utilização, manipulação, armazenamento, descarte e a obediência fitossanitária brasileira, sendo necessárias orientações para o esclarecimento dos produtores da região de Três Corações.

\section{REFERÊNCIAS}

AGOSTINETTO, D.; PUCHALKI, L. E. A.; AZEVEDO, R.; STORCH, G.; BEZERRA, A. J. A.; GRÜTZMACHER, A. D. Utilização de equipamentos de proteção individual e intoxicações por agrotóxicos entre fumicultores do município de Pelotas-RS. 
Pesticidas Revista Ecotoxicologia e Meio Ambiente, v. 8, p.45-56, 1998.

ALVES FILHO, J. P. Uso de agrotóxicos no Brasil: controle social e interesses corporativos. São Paulo: Annablume, 2002.

ANDEF. Associação Nacional de Defesa Vegetal. $2010 . \quad$ Disponível em: <http://agrobyte.com.br/index.php?pag=meioambiente \&ambiente $=$ embalagens $>$. Acesso em: 4 de outubro de 2017.

BEDOR, C. N. G., RAMOS, L. O., PEREIRA, P. J., RÊGO, M. A. V., PAVÃO, A. C., \& AUGUSTO, L. G. D. S. Vulnerabilidades e situações de riscos relacionados ao uso de agrotóxicos na fruticultura irrigada. Revista brasileira de Epidemiologia. v. 12, n. 1, p. 39-49, 2009.

BRIGANTE, J.; ESPÍNDOLA, E. L. G.; POVINELLI, J.; ELER, M. N.; SILVA, M. R. C.; DORNFELD, C. B.; NOGUEIRA, A. M. Avaliação ambiental do rio Mogi-Guaçu: resultados de uma pesquisa com abordagem ecossistêmica. São Carlos: Rima, 2002. 58p.

CASTRO, M. G. G. M.; FERREIRA, A. P.; MATTOS, I. E. Uso de agrotóxicos em assentamentos de reforma agrária no Município de Russas (Ceará, Brasil): um estudo de caso. Epidemiologia e Serviços de Saúde, v. 20, n. 2, 2011.

FOSTER, S.; HIRATA, R.; GOMES, D.; D’ELIA, M.; PARIS, M. Proteção da qualidade da água subterrânea: um guia para empresas de abastecimento de água, órgãos municipais e agências ambientais. São Paulo: SERVMAR, 2006.

LONDRES, F. "Agrotóxicos no Brasil: um guia para ação em defesa da vida." Rio de Janeiro: ASPTA-Assessoria e Serviços a Projetos em Agricultura Alternativa. 2011. 190p.

NEVES, M. C. P. Projeto estratégico de apoio à agricultura orgânica: agricultura orgânica como ferramenta para a sustentabilidade dos sistemas de produção e valorização dos produtos agropecuários. Brasília: Embrapa. 2001. 32p.

OLIVEIRA-SILVA, J. J.; ALVES, S. R.; MEYER, A.; PEREZ, F.; SARCINELLI, P. D. N.; MATTOS, R. D. C. O.; MOREIRA, J. C. Influência de fatores socioeconômicos na contaminação por agrotóxicos. Brasil. Revista de saúde, V. 35, N. 2, pp. 130-135, 2001.

QUINTELA, E.D. Manejo integrado dos insetos e outros invertebrados: pragas do feijoeiro. Informe Agropecuário, v. 25, p. 113-136, 2004.
RAMOS, A.; SILVA FILHO, J. F. Exposição a pesticidas, atividade laborativa e agravos à saúde. Revista Médica de Minas Gerais, v. 14, p. 41-45, 2004.

RECENA, M. C. P.; CALDAS, E. D.; PIRES, D. X.; PONTES, E. R. J. Pesticides exposure in Culturama, Brazil-knowledge, attitudes, and practices. Environmental Research, v. 102, n. 2, 230-236, 2006.

ROCHA, L. F. Pesquisa avalia o risco de contaminação de solos e águas. Revista Minas Faz Ciência, n. 18, 2004. Disponível em: <https://www.mastereditora.com.br/periodico/201801 03_165659.pdf> Acesso em: 12/05/2017.

SANTOS, M. L. e PYHN, E. G. Idade biológica, comportamento humano e renovação celular. São Paulo: SENAC, 2003.

SCORZA JUNIOR, R. P.; NÉVOLA, F. A.; AYELO, V. S. Avaliação da contaminação hídrica por agrotóxico. Boletim de pesquisa e desenvolvimento. EMBRAPA Agropecuária Oeste, Dourados, 2010.

SILVA, J. M. Saúde do Agricultor Familiar e População Exposta ao uso de Agrotóxico: guia de estudos. Lavras: UFLA, 2015.

SOARES, W.; ALMEIDA, R. M. V. R.; MORO, S. Trabalho rural e fatores de risco associados ao regime de uso de agrotóxicos em Minas Gerais. Brasil, Caderno Saúde Pública, v. 19, n. 4, p. 1.117-1.127, 2003.

TRAPÉ, A. Z. O caso dos agrotóxicos. In: ROCHA, L. E.; RIGOTTO, R. M.; BUSCHINELLI, J. T. P. Isto é trabalho de gente? Vida, doença e trabalho no Brasil. Petrópolis: Vozes, p. 569-593, 1993.

VEIGA, M. M.; SILVA, D. M.; VEIGA, L. B. E.; FARIA, M. V. D. C. Análise da contaminação dos sistemas hídricos por agrotóxicos numa pequena comunidade rural do Sudeste do Brasil. Caderno de Saúde Pública, v. 22, n.11, p. 2391-2399, 2006.

\section{Francisco Carlos Pedro}

Bacharel em Agronomia pela Universidade Vale do Rio Verde (UninCor), Três Corações, Minas Gerais. Extensionista da Empresa de Assistência Técnica e Extensão Rural do Estado de Minas Gerais (Emater MG).

\section{Aurivan Soares de Freitas}

Mestre e doutor em Fitopatologia pela Universidade Federal de Lavras (UFLA). Professor na Universidade Vale do Rio Verde (UninCor). 


\section{Eliana Alcantra}

Mestre e doutora em Entomologia pela Universidade

Federal de Lavras (UFLA). Professora na

Universidade Vale do Rio Verde (UninCor).

\section{Jeferson Arantes Braz}

Bacharel em Agronomia pela Universidade Vale do Rio Verde (UninCor), Três Corações, Minas Gerais.

\section{Júnia Rafael Mendonça Figueiredo}

Mestre e doutora em Fisiologia Vegetal pela

Universidade Federal de Lavras (UFLA). Professora na Universidade Vale do Rio Verde (UninCor). 